\title{
Recent Advances in Bio-inorganic Chemistry
}

\section{FOREWORD}

Bio-inorganic chemistry has developed rapidly in recent years. A number of laboratories in India have made significant contributions to this area. The motivation in bringing out this special issue on Bio-inorganic Chemistry is to highlight the recent work emerging from India in this important and fascinating interdisciplinary area.

The second objective in bringing out this special issue is to pay homage to Professor Bhaskar Maiya, an eminent inorganic chemist, who suddenly passed away in Hyderabad on 21 March 2004. The topics covered in this special issue - porphyrin chemistry, supramolecular chemistry and photochemistry - were dear to Prof Maiya's heart. In addition to his significant contributions to the field of bio-inorganic chemistry, Prof. Maiya was involved in popularizing science and inculcating scientific spirit and temper among young students. Prof Maiya served as a member of the Editorial Board of this Journal for several years and the Journal greatly benefited from his help and advice.

As a Guest Editor, I thank the Academy for bringing out this special issue and the authors and the referees for their timely support. 